\section{William Wallace Campbell}

By Marcus Benjamin, Ph.D.

$\mathrm{F}^{\mathrm{OR}}$ the first time in the history of the American Association for the Advancement of Science that great scientific organization will meet on the Pacific Slope and its sixty-seventh meeting will be held in San Francisco during the week beginning on August 2nd. Whenever practicable the presiding officer has been selected from those scientists who lived in the vicinity of the meeting place, and so this year the director of the Lick Observatory on Mount Hamilton has been wisely chosen as America's most representative man of science.

William Wallace Campbell is of Scotch ancestry, as his name clearly indicates, and is the son of Robert Wilson and Harriet Welsh Campbell. He was born in Hancock County, Ohio, on April 11th, 1862, and there spent his boyhood days.

His early studies were made in the public schools in the vicinity of his home and were continued until 1877 when he entered the Fostoria High School, where he remained for three years. For a year thereafter he followed the excellent practice of teaching and so learned from experience how best he himself might impart knowledge. Ambitious for greater information, he entered in 1882 the University of Michigan in Ann Arbor where he was graduated four years later with the degree of B.S. in civil engineering.

He was promptly called to fill the chair of mathematics and astronomy in the University of Colorado in Boulder, but in 1888 he returned to his alma mater to accept the appointment of instructor in astronomy and assistant in the Detroit Observatory, which place he held until 1891, making a specialty during these year of comet observations and orbit computations.

His next appointment was to the charge of the spectroseopic department in the Lick Observatory, then under the direction of the late Prof. Edward S. Holden, where he gave much attention to the study of new tars, variable stars, various classes of bright-line stars comets, etc. Later he was specially engaged in determining the radial velocity of the brighter stars by means of the Mills spectrograph attached to the 36-inch refracting telescope.

On the death of the lamented Keeler in August, 1900 he was made acting director of the Lick Observatory which appointment was made permanent on Januar 1st, 1901, since when he has continued to hold this most important astronomical directorship in America and one indeed which is scarcely equaled in prestige anywhere in the world. While he has been director, there has naturally been much routine work to be attended to, but he has found time to continue his observations of the radial velocities of the stars, and in recent years to measure the radial motions of about seventy nebulæ, both at Mount Hamilton and in Santiago, Chili, a work of remarkable importance. It was in connection with these undertakings that he organized in 1903 the expedition to Santiago through the munificence of the lat tion to Santiago through the munificence of the late
Mr. D. O. Mills, which had for its purpose the deterMr. D. O. Mills, which had for its purpose the determination of the motions of the bright stars in southern skies that were not visible at Mount Hamilton, thus ex tending the work over the entire heavens. Director Campbell and his colleagues and associates in both hemispheres have observed the motions of about seventeen hundred stars in all parts of the sky. The result for the individual stars have been used by him to study the motion of the solar system through space, the motions of the stars as functions of their spectral classes, the scale on which the stellar system is constructed, the evolution of double-star systems, and other problems of large cosmical significance.

Director Campbell has had charge of the following eclipse expeditions that were sent out from the Lick Observatory, namely, to Jeur, India, in 1897-8; to Thomaston, Ga., in 1900; to Alhama, Spain, in 1905; t
Flint Island, Pacific Ocean, in 1908; and to Kief, Russia, in 1914.

The results of his many valuable contributions to science have for the most part appeared in such important publications as the Astronomical Journal, Astronomische Nachrichten, Astrophysical Journal, Bulletins of the Lick Observatory, and the publications of the Astronomical Society of the Pacific. It is obviously mpossible to discuss these in detail in this place, but of their merit I venture to give President Mas's words when he presented the gold medal of the Royal Astronomical Society in 1906 to Prof. Campbell "for his spectroscopic researches, which have greatly increased our knowledge of stellar motions." He said, "our science is indebted to him for important advances secured by

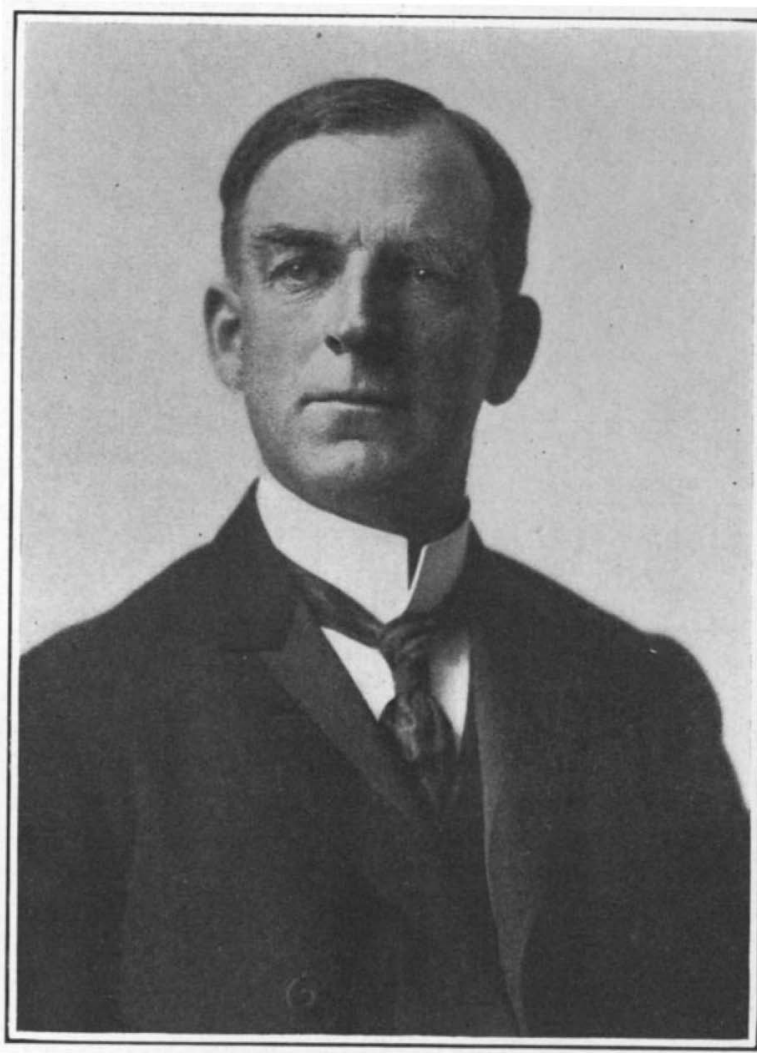

William Wallace Campbell.

President American Association for the Advancement of Science.

researches most excellently planned, and carried out with a skill, persistence, and energy which command our highest admiration."

Prof. Campbell has enriched the literature of his chosen science by two large volumes. The first of these "Elements of Practical Astronomy" (1899) was written "as a text-book during his professorial vears at the University of Michigan and is still extensively used in many universities. His Silliman lectures were collected into a volume entitled "Stellar Motions" (1913), which is described by reviewers as a praiseworthy treatise that presents a "complete summary of research on stellar motions, especially as determined by the spectroraph" It is also referred to as "an epoch-making volgraph." for which all astronomers will heartily thank the ume for

Among the many recognitions of his unusual ability as an astronomer that have come to him may be mentioned his selection as Silliman lecturer at Yale University in 1909-10, and his appointment by his colleagues in the National Academy to deliver the William Ellery Hale lectures in 1914. He has received the Lalande medal of the French Academy of Sciences (1903); the medal of the Royal Astronomical Society of London (1906) ; the Draper medal of the National Academy of
Sciences (1906); the Janssen medal of the French Academy of Sciences (1910); and the Bruce international medal of the Astronomical Society of the Pacific (1914). From his own University of Michigan he received in 1899 the degree of M.S., and in 1905 that of Sc.D., while a similar degree was conferred upon him by the University of Pittsburgh in 1900, and that of LL.D., from the University of Wisconsin in 1902

Director Campbell is a foreign associate of the Roya Astronomical Society, a member of the Astronomische Gesellschaft, and of the Swedish Academies of Sciences in Upsala and Stockholm, and of the Academy of Sciences in Montpellier, France, as well as a foreign member of the Society of Italian Spectroscopists. In the United States he is a member of the American Astronomical Society, the Astronomical Society of the Pacific the American Academy of Arts and Sciences, the American Philosophical Society, and since 1902 of the National Academy of Sciences.

His membership in the American Association for the Advancement of Science is comparatively recent; fo he joined it only at its Denver meeting in 1901 . He was quickly advanced to the grade of fellow, and at the Philadelphia meeting last winter was selected by his scientific colleagues to preside over the first meeting to be held west of the Rocky Mountains, thus achievin the "blue ribbon" of science in the United States. Few astronomers equal him and none surpasses him.

\section{New War Cars for Our Army}

A FLEET of eight military cars recently left Chicago

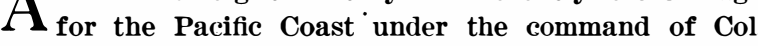
R. P. Davidson, head of the Northwestern Military and Naval Academy, accompanied by expert observers from the War Department.

Included in the fleet is an officers' reconnaissance car, equipped with special Ross military rifles, map tables, and instruments for making road and contour maps, a dictating machine, a periscope for observations from be hind walls or other defenses, altitude indicators, range and elevation finders; in fact, every instrument helpful in making a reconnaissance report. A wireless car has a telescopic mast mounted on the running board, and is equipped with a special electric generator capable of producing a current of 110 volts. A second car carries, in addition to its wireless outfit, a Colt automatic rapid-fire gun and a powerful electric searchlight wit heliograph shutter.

In the field kitchen cooking is done by means of a fireless cooker operated by electricity; there is also a general kitchen equipment. Special operating tables, surgical instruments and an X-ray apparatus make up the equipment of the hospital car.

A complete armor of bullet-proof steel, with opening for rifle fire, is provided for another car, which als mounts a Colt automatic rapid firer. This car carrie a simple rope and windlass arrangement which would be found useful in actual warfare in extricating the car from a ditch, or dragging it up a steep embankment. One of the cars is designated as a quartermaster's car, and carries a Colt automatic gun, while there is also a baloon destroyer armed with a Colt rapid firer. The balloon destroyer is a hero of the Glidden tour of 1910 , and by this time has had close to 80,000 miles of hard road travel and field work during different army maneuvers.

Theft Preventer for Automobiles.-Patent No. 1,139,757, to Leo Ehrlich of St. Louis, assignee of Francis K. Fassett of Dayton, Ohio, provides an automobile with means so that it may be disabled and with a number independent manually operated elements, one of which may be operated to remove the disability so that the automobile can be operated, while if any other one of the elements be operated it will not remove the disability but will cause an alarm to sound.

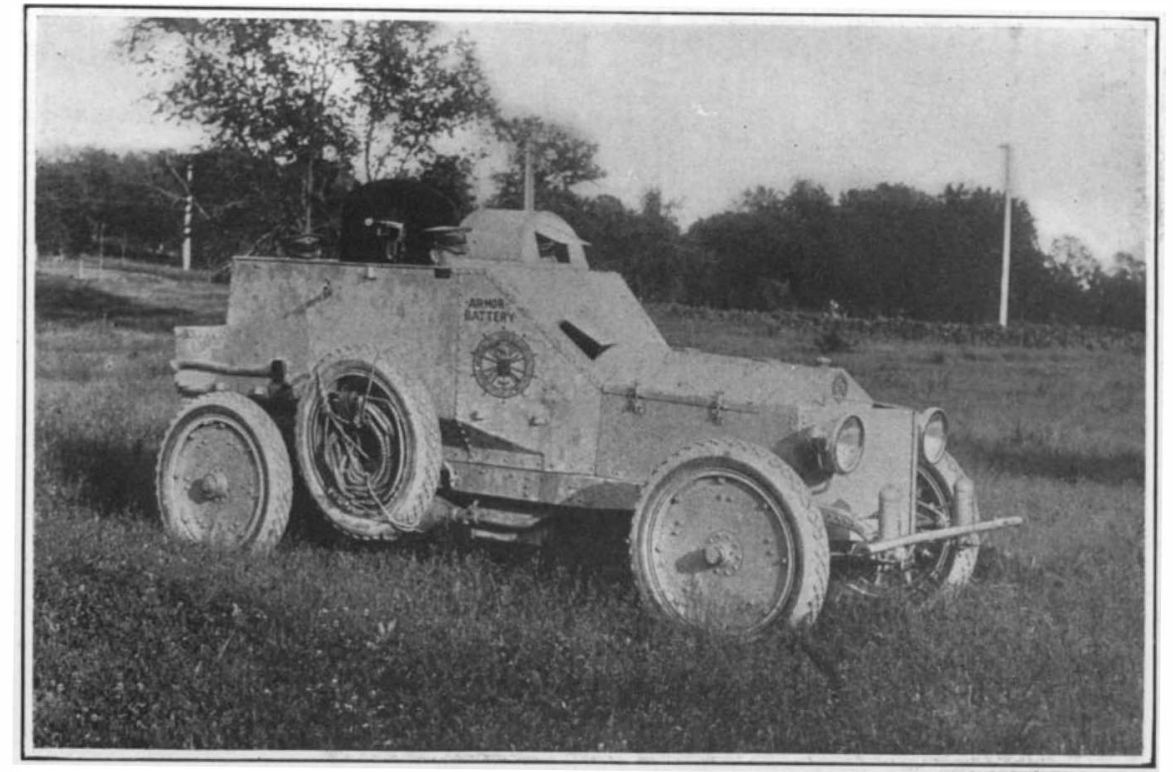

An armored automobile for the United States Army.

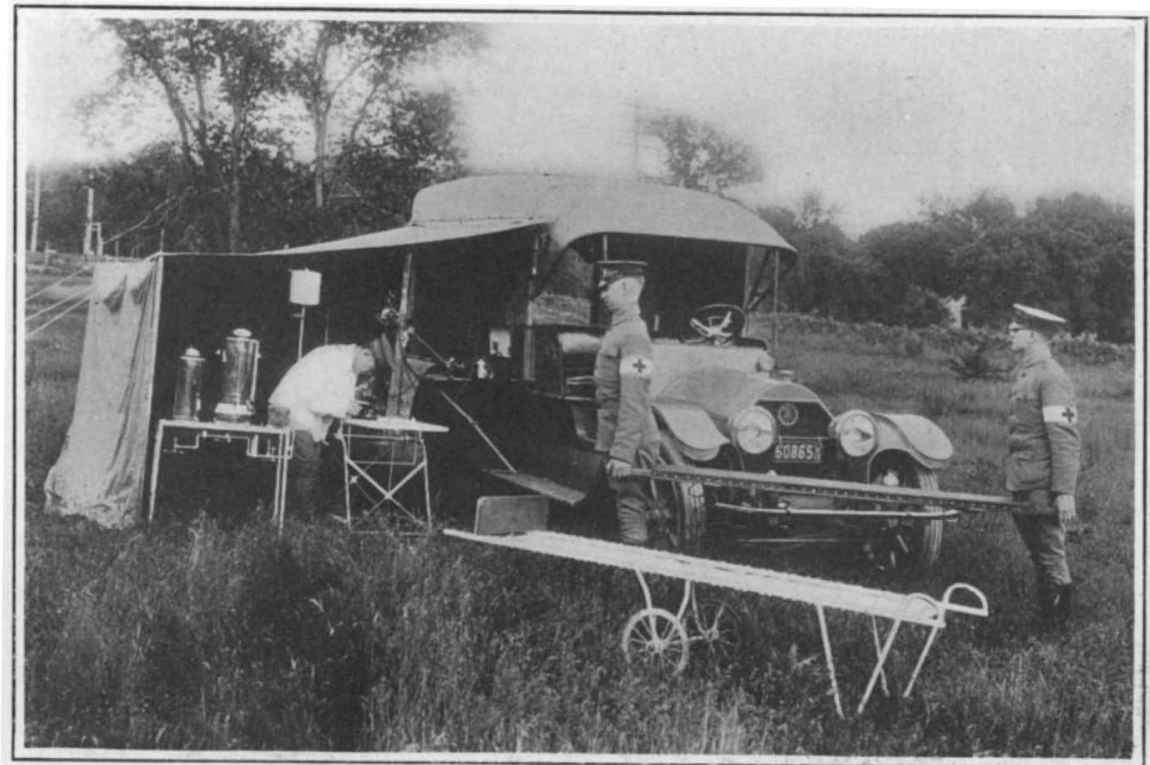

The hospital car with its equipment set up for service. 